\title{
$\angle S$ Research Square

\section{On the influence of heat treatment in suppressing the layer orientation effect in finishing of electron beam melted Ti6Al4V}

Abdulmajeed Dabwan ( $\square$ adabwan@ksu.edu.sa )

King Saud University https://orcid.org/0000-0003-4907-6615

\section{Saqib Anwar}

King Saud University

Ali M. Al-Samhan

King Saud University

Mustafa M. Nasr

King Saud University

\section{Research Article}

Keywords: Electron beam melting, titanium alloy Ti6Al4V, part orientations, heat-treated part, microstructure

Posted Date: May 3rd, 2021

DOI: https://doi.org/10.21203/rs.3.rs-331440/v1

License: (c) (i) This work is licensed under a Creative Commons Attribution 4.0 International License. Read Full License

Version of Record: A version of this preprint was published at The International Journal of Advanced Manufacturing Technology on October 8th, 2021. See the published version at https://doi.org/10.1007/s00170-021-07995-3. 


\section{Abstract}

Electron beam melting (EBM) is gaining more interest due to its near-net-shape production and ability to process difficult to manufacture materials, such as titanium alloys. However, due to the poor surface quality of the EBM parts, finishing operations, such as machining, are required. The main issue in the finishing of the EBM parts is their directional properties that lead to different surface roughness values for different part orientations for the same employed machining parameters. In this study, EBM Ti6AI4V parts were subjected to heat treatment to suppress the effect of the part/layers' orientations effect during the finish milling process. Three different heat treatments were employed to the as-fabricated EBM Ti6Al4V parts. The fine lamellar microstructure was set as a target from the heat treatment due to its overall superior mechanical properties and also, to keep a fair comparison in the machining of the asfabricated and heat-treated EBM Ti6Al4V parts. The results of the heat treatments showed that the EBM Ti6Al4V parts heated at $600^{\circ} \mathrm{C}$ for 3 hours and then air-cooled exhibited the same fine lamellar microstructure and microhardness as that of the as-fabricated EBM parts. The other two heat treatments including heating at $950^{\circ} \mathrm{C}$ and $800^{\circ} \mathrm{C}$ for 2 hours followed by air cooling were not able to maintain the fine lamellar structure due to the increase in the width of the alpha grains. The as-fabricated and heattreated EBM Ti6Al4V parts were subjected to the milling operation by considering the three possible parts/layers orientation with respect to the tool feed directions. The milling results showed that the asfabricated parts showed up to a $27 \%$ difference in surface roughness for different part orientations. In contrast, the heat-treated parts showed uniform surface roughness for the three part orientations with a variation of $8 \%$. Similarly, considerable differences were observed in the surface integrity and the machined surface microhardness (18\%) of the as-fabricated EBM parts as compared to the heat-treated parts) $2 \%$ ). The heat-treated parts showed more uniform and superior surface morphology across all the part orientations. This is because of the more uniform microstructure, less porosity, higher consolidation of the EBM layers, and elimination of the columnar grains in the case of the heat-treated parts as compared to the EBM parts. This study revealed that in the case of the heat-treated EBM part the effect of part orientation with respect to milling tool feed direction was almost removed.

\section{Introduction}

Ti6Al4V titanium alloy is one of the most commonly used materials in the automotive, biomedical, petroleum, and aerospace industries because of its associated corrosion resistance, biocompatibility, and the good strength-to-weight ratio [1]. Ti6Al4V is considered to be the most widely used type of titanium alloy representing over $50 \%$ of its global production, 80 percent of which is used in the medical and aerospace industries [2]. At the same time, this material is considered to be hard to machine, though [3].

Electron beam melting (EBM) is a metal powder bed fusion additive manufacturing (AM) technology that enables three dimensional (3D) near-net-shaped parts to be produced directly from computer models [4]. EBM process has the capability to produce simple to complex shape parts in Ti6Al4V. Therefore, the EBM is attracting considerable interest among surgical implant manufacturers as a near-net type technology [5]. The EBM machine reads in data from a digitally scanned 3D model, cut into individual layers, and 
lays out successive $60 \mu \mathrm{m}$ to $100 \mu \mathrm{m}$ thick metal powder layers that are slowly melted to create the product model via the regulated electron beam scanning process [6]. The low residual stresses and good dimensional precision differentiate EBM from other metal-based AM processes [7]. Nevertheless, some defects remain, including the high roughness of the produced surfaces and the need for supporting structures [8].

In the view of surface quality, EBM parts require finishing (usually machining) to produce the final usable surface in terms of surface performance $[5,9,10]$ and SLM Parts require finishing also [11]. The surface integrity of the machined surface and the subsurface essentially control a component's functional performance to a large extent [12]. Several studies [13-17] on conventional titanium alloys have been carried out to understand the impact of machining on the generated surfaces. At the same time, very little knowledge is available for machining the parts developed that are produced by additive manufacturing technologies [18]. Previous studies reported that there are additional challenges in machining the EBM parts as compared to their wrought counterparts [5]. This is because the EBM parts show more strength as compared to the wrought parts. Furthermore, because of the directional properties, as highlighted by $[4,19]$ the machining of the EBM part could become difficult. In addition to the consolidated EBM layers within the part, varying surface characteristics of different faces can further complicate the machining. For example, with the same machining parameters, the EBM part exhibited different surface roughness for different faces of the EBM part $[9,20]$. It was emphasized in these studies that care must be taken to select the tool feed direction with respect to the EBM layers/part orientations to achieve good surface quality during finishing the EBM parts. Anwar et al. [9] highlighted the three possible EBM part orientations to choose from during milling. The purpose of this study is to propose a solution for minimizing the differences in milling performance across different EBM part orientations/faces for improving their surface quality. Heat treatment before machining is adopted as a possible solution to minimize/remove the effect of the EBM layers/part orientations during machining.

Several studies have been performed on the heat treatment of the EBM Ti6Al4V parts for improving their microstructure and mechanical proprieties. Heat treatments are usually applied to achieve specific types of microstructures and associated mechanical properties, which cannot be directly achieved by EBM process [21,22] and by selective laser melting (SLM) process [23]. On the other hand, some authors have also reported that as-fabricated Ti6AI4V EBM parts exhibit superior properties as compared to the heattreated parts, and can be used in several applications. For instance, Raghavan et al [22] presented a broad range of post-processing heat treatment cycles performed on EBM Ti6AI4V parts, and developed heat treatment correlations with mechanical properties and microstructure. The optimum heat treatment was identified to obtain the best mechanical properties (hardness and tensile strength) and microstructure. Their findings showed that the EBM produced parts exhibited columnar grains microstructure with very fine $\alpha-\beta$ spacings resulting in strong overall mechanical properties. The asfabricated EBM samples exhibited superior strength as compared to that of the heat-treated samples due to very fine a lath morphology. The microstructure of an EBM fabricated Ti6AI4V part has a very fine lamellar structure because of the intrinsically high solidification rate during the process [24]. The solidification factors are responsible for weak $\beta$ texture development and microstructural differences [25]. 
Another study showed that the microstructural coarsening caused by heat treatment results in lower yield strength levels [21]. Therefore, as fabricated EBM part microstructure is preferable owing to its attractive mechanical properties.

From the literature review, it can be seen that the machining of the EBM parts is required for achieving the quality of surface needed in many applications. However, the machining of the EBM parts is a challenging task due to the directional properties resulting from the melted layers' orientations. In this study, heat treatment is used as a tool to suppress the effects of the EBM layers' orientations during machining. However, during the heat treatment, it is tried to retain the same microstructure as that of the as-fabricated EBM parts due to its benefits mentioned in the previous studies [22, 24]. To keep a fair comparison between the machining of the as-fabricated and heat-treated EBM parts, the heat treatment process was selected such that it would yield the same hardness and microstructure as that of the asfabricated EBM parts. However, no previous knowledge exits in the literature on such a heat treatment that would result in the same microstructure and hardness, like that of the as-fabricated EBM samples.

\section{Experimentation}

Figure 1a shows the EBM setup from ARCAM AB, Mölndal, Sweden that was used to produce parts with the dimensions of $30 \times 30 \times 10 \mathrm{~mm}$, as shown in Fig. 1b. The used Ti6Al4V powder has a mean particle size of $71 \mu \mathrm{m}$. The chemical composition of the powder was (wt. \%); aluminum = 6.04, vanadium $=4.05$, carbon $=0.013$, iron $=0.0107$, oxygen $=0.13$ and balance titanium. The surface roughness (Sa) of the asfabricated EBM part on the top face and side faces is $6 \mu \mathrm{m}$ and $21 \mu \mathrm{m}$, respectively. Although the EBM parts are produced according to optimized parameters in previous works [26, 27], as shown in Table 1, On both side and top surfaces, the average surface roughness values are still too low for many applications. For example, the requirement of surface roughness in aerospace parts range from $0.2-0.25 \mu \mathrm{m}$ [28], and for femoral medical implants is Ra < $0.2 \mu \mathrm{m}$ [29]. Therefore, a secondary operation for the EBM parts is necessary in order to provide a good surface finish. The secondary operation in this study is carried out via the milling process. Figure 1c shows the three-axis CNC vertical milling machine, Mori DMG (DMC 635 $\checkmark$ Ecoline), Germany, capable of the feed rate of $24 \mathrm{~m} / \mathrm{min}$, spindle speed of $8000 \mathrm{rpm}$, and a positioning resolution of $1 \mu \mathrm{m}$. This machine was used for investigating and comparing the machining performance of the as-fabricated and heat-treated EBM Ti6AI4V parts with respect to three possible part/layers' orientations, as shown in Fig. 1d. Figure 2 shows the detail of the three possible part/layers' orientations that can be encountered during the milling process to enhance the surface finish of the produced EBM part. In the first case, the tool was fed across the EBM layers (Face A in Fig. 1d), in the second case, the tool was fed parallel to the EBM layers (Face B in Fig. 1d), and in the third case, the tool was fed within the plane of EBM layers (Face $C$ in Fig. 1d). A solid carbide end mill cutter was used in the milling experiments. Table 2 summarizes the cutting parameters for milling tests, which are used to determine the effect on the milling quality of EBM component orientation and heat treatment. Table 2 listed process parameters belong to the range of previous studies for machining Ti6Al4V as provided by $[13,30,31]$.

\section{Table 1}


Default EBM parameters from ARCAM for producing Ti6Al4V parts [26, 27].

\begin{tabular}{|llllllll|}
\hline $\begin{array}{l}\text { EBM } \\
\text { Parameters }\end{array}$ & $\begin{array}{l}\text { Beam } \\
\text { current }\end{array}$ & $\begin{array}{l}\text { Acceleration } \\
\text { voltage }\end{array}$ & $\begin{array}{l}\text { Focus } \\
\text { offset }\end{array}$ & $\begin{array}{l}\text { Line } \\
\text { offset }\end{array}$ & $\begin{array}{l}\text { Scan } \\
\text { speed }\end{array}$ & $\begin{array}{l}\text { Powder layer } \\
\text { thickness }\end{array}$ & $\begin{array}{l}\text { Preheat } \\
\text { temperature }\end{array}$ \\
\hline Values & $15 \mathrm{~mA}$ & $60 \mathrm{kV}$ & $3 \mathrm{~mA}$ & $\begin{array}{l}0.1 \\
\mathrm{~mm}\end{array}$ & $\begin{array}{l}4530 \\
\mathrm{~mm} / \mathrm{s}\end{array}$ & $0.05 \mathrm{~mm}$ & $750^{\circ} \mathrm{C}$ \\
\hline
\end{tabular}

\section{Table 2}

Process parameters used for milling the EBM parts

\begin{tabular}{|llll|}
\hline Parameters & Notation & Values & Units \\
\hline Cutting speed & $\mathrm{V}$ & 50,80 & $\mathrm{~m} / \mathrm{min}$ \\
\hline Feed rate & $\mathrm{f}$ & 30 & $\mathrm{~mm} / \mathrm{min}$ \\
Axial depth of cut & $\mathrm{d}_{\mathrm{A}}$ & $0.4,0.6$ & $\mathrm{~mm}$ \\
\hline Radial depth of cut & $\mathrm{d}_{\mathrm{R}}$ & 4.8 & $\mathrm{~mm}$ \\
Part/layers orientation & - & Face A, Face B, Face C & - \\
\hline
\end{tabular}

Two types of EBM Ti6Al4V parts were used in the milling experiments; (i) as-fabricated EBM parts, and (ii) the heat-treated EBM parts. The purpose of the heat treatment was to check its effectiveness in suppressing the effect of the layers' orientations during machining or in other words to suppress the directional properties of the EBM part. It should be noted that already several studies have been reported on the heat treatment of the as-fabricated EBM parts to acquire the desired microstructures [21, 22]. However, the heat treatment was therefore used as a tool in this study to counteract the negative effects of the orientations of the EBM layers during machining. Furthermore, to ensure a fair distinction between the machining of the as-fabricated and heat-treated parts, the heat treatment was chosen in such a way that it would produce approximately the same microstructure and hardness as that of the as-fabricated EBM parts. Nevertheless, no prior knowledge exists in the literature on such a heat treatment that would result in the same microstructure and hardness as-fabricated EBM parts. Therefore, several heat treatment recipes were employed, as listed in Table 3, to obtain the heat-treated EBM parts with the same microstructure and hardness. This was done to exclusively study the effect of the heat treatment on the machining behavior, instead of the microstructural or hardness changes. As it is well known that, the microstructure and hardness significantly affect the machining of the material [32]. Whereas, the purpose of this work is to study the effect of heat treatment in terms of extra consolidation time given to the samples to diminish the layers' orientation effect.

For microstructure observation of the as-fabricated and heat-treated EBM parts, the parts were ground with grade P220, P400, P600, P800, P1000, P1500, and P2500 silicon carbide papers, fine polished with 
alumina suspension, and etched using Kroll's reagent. Microstructural images were taken using a Metkon IMM 901 metallurgical microscope.

Heat treatment of the as-fabricated EBM parts was carried out in a furnace (Nabertherm), Germany, which can heat parts up to $3000^{\circ} \mathrm{C}$, as shown in Fig. 3a. To evaluate the milling performance, four responses were measured including surface roughness, microstructure surface morphology, and micro-hardness. The illustration of the milling setup is shown in Fig. 3b. Figure $3 \mathrm{c}$ shows the optical microscope used to obtain the images of the porosity. After milling for each of the three orientations (Face A, Face B, and Face $\mathrm{C}$ ), scanning of an area of $2.2 \mathrm{~mm} \times 1.7 \mathrm{~mm}$ obtained an average surface roughness ( $\mathrm{Sa}$ ) on machined surfaces. For every orientation, the average surface roughness of five areas along the cutting direction was taken. A 3D (Contour GT-K) optical profilometer from Bruker, Germany, was used to scan the surface roughness ( $\mathrm{Sa}$ ) of the machined as-fabricated and heat-treated EBM parts, as shown in Fig. 3d. Jeol JCM 6000 Plus scanning electron microscope (SEM) from Japan was used to examine the surface morphology of the machined as-fabricated and heat-treated EBM parts, as shown in Fig. 3e.

Microhardness indentation measurements were taken to see the effect of the heat treatments and to compare the hardness of the heat-treated EBM samples with the as-fabricated EBM parts. A Struers A / S, Ballerup, Austria, Durascan 10 Vickers hardness (HV) device was used to test microhardness, with a load of $100 \mathrm{gf}(0.1 \mathrm{~N})$ applied for a dwell time of $15 \mathrm{~s}$, as shown in Fig. 3f. Micro-hardness readings were also recorded on Faces A, B, and C (see Fig. 1c) for both the as-fabricated and heat-treated EBM parts after the milling experiments. The average of five micro-hardness readings was taken from each face.

\section{Table 3}

Different heat treatment conditions used for the EBM parts.

\begin{tabular}{|llll|}
\hline & Temperature $\left({ }^{\circ} \mathrm{C}\right)$ & Time $(\mathbf{h})$ & Cooling environment \\
\hline Heat treatment-1 [21, 33] & 950 & 2 & In air \\
\hline Heat treatment-2 [34] & 850 & 2 & In air \\
\hline Heat treatment-3 $[4,34]$ & 600 & 3 & In air \\
\hline
\end{tabular}

\section{Results And Discussion}

\subsection{Microstructure and micro-hardness}

Microstructure and micro-hardness of the heat-treated parts are presented in Fig. 4 and Fig. 5, respectively. EBM parts would be ideal to use in the as-fabricated form without any heat treatment. This is because the microstructure of the EBM fabricated part has a fine lamellar structure [7, 24], which imparts attractive mechanical properties to the produced parts [35]. Therefore, several heat treatments were performed to find the one that can keep microstructure and micro-hardness as that of the asfabricated EBM parts. The purpose of the heat treatment is to suppress the effect of EBM layers' 
orientations with respect to the milling tool feed direction without affecting the mechanical properties of the EBM parts. The increase in temperature can lead to an increase in the width of the a phase which gives more brittleness and reduction in fatigue life, as reported by Raghavan et.al [22].

The microstructure of the as-fabricated EBM part is shown in Fig. 4a. The microstructure for EBM Ti6Al4V has alpha ( $a$ ) and beta ( $\beta$ ) phases, as highlighted in Fig. $4 a$. The mechanical properties of $a+\beta$ titanium alloys are mainly governed by the a phase, as its strength and hardness is higher than the $\beta$ phase [36]. Refined lamellar microstructure with $\alpha$ and $\beta$ phases was observed for the as-fabricated EBM parts (see Fig. 4a). Similar microstructures of the as-fabricated EBM parts were also found in the other studies [4, 37].The microstructures of the heat-treated EBM parts are shown in Fig. 4. The most common treatment reported in literature for EBM Ti6Al4V is heating at $950^{\circ} \mathrm{C}$ for two hours and then air cooled (Heat treatment 1 in Table 3) [21, 33], which was selected in the first place. However, it did not produce the fine lamellar structure like the as-fabricated EBM part. The microstructure of $950^{\circ} \mathrm{C}$ appears to have coarser a laths compared to the microstructure of the as-fabricated part. In addition, the width of a grains are much bigger than in the microstructure of the as-fabricated part due to extra heat given to the part during heat treatment. The heat treatment- 2 involved heating the samples at $850^{\circ} \mathrm{C}$ for two hours and then air cooled to keep/obtain the fine lamellar microstructure of the EBM parts. Still, the fine lamellar structure could not be maintained, as shown in Fig. 4c. The microstructure still has higher width of a phase than in the microstructure of as-fabricated part because of increase in temperature given to the part during heat treatment. Furthermore, the proportion of the beta phase is significantly higher than in the as-fabricated EBM parts. The heat treatment-3 involved heating the part at $600^{\circ} \mathrm{C}$ for three hours followed by air cooling. Similar fine lamellar $\alpha$ and $\beta$ microstructure was obtained after the heat treatment- 3 as that of the as-fabricated EBM part, as can be seen by comparing Fig. 4a and Fig. 4d.

Moreover, the micro-hardness readings have the trend with the microstructures for all the heat-treated EBM parts as compared to the as-fabricated part. This is because the increase in temperature which can lead to an increase in the width of the a phase and adds more brittleness, as shown in Fig. 5 . For the proceeding results, only the heat-treated samples with $600^{\circ} \mathrm{C}$ are used because they give the same microstructure and micro-hardness of the as-fabricated part and the other heat-treated samples were not used.

\subsection{Surface roughness}

Figure 6 shows the surface roughness ( $\mathrm{Sa}$ ) comparison for each of the three part orientations for the asfabricated and heat-treated EBM parts. For the as-fabricated part, (see Fig. 6a) there is a significant difference between the highest value of average surface roughness of Face $C$ orientation and the Face $A$ and Face $B$ orientations. The highest Face $C$ roughness value $(0.15 \mu \mathrm{m})$ and the lowest Face $A$ value $(0.11 \mu \mathrm{m})$ are almost $27 \%$ significantly different. In addition, the difference is almost $13 \%$ between Face $\mathrm{C}$ and Face B. This difference is because the tool interacts with one single EBM layer ( $50 \mu \mathrm{m}$ thick) while machining along the Face $\mathrm{C}$ orientation and exercises compressive forces at the EBM layer interface which cause bonded layers to tear, which leads to a high roughness. However, if the tool is fed in the Face A direction, the tool interacts/cut the group of layers with radial depth while exercising force on the layer 
bonds/interfaces, thus preventing tearing of the adjacent layers. When the Face B orientation is applied, while the tool is fed throughout the layer group, the layer interfaces still undergo the tensile forces and tearing of the bonds may occur. This contributes to moderate roughness in the case of Face B direction.

In contrast, there is no significant difference in the surface roughness for the three part orientations for the heat-treated EBM part, as shown in Fig. 6b. This is because the layer orientations were eliminated in all directions and the layers are more fused and consolidated due to the extra heat given to the part during heat treatment. Another factor that contributes to more homogeneous roughness across all part orientations is that the porosity in the heat-treated EBM part is significantly less than the as-fabricated EBM parts. A comparison of the porosity of the as-fabricated and heat-treated EBM parts is shown in Fig. 7, where the porosity can be seen as bright regions and the black background indicates the solid part. Figure 7 shows that the porosity reduced significantly after heat treatment. It has been previously reported that porosity within the EBM part is unevenly distributed across different orientations [4], which results in non-uniform machining across different faces. However, after the heat treatment, the layers are fused further and the porosity is almost diminished, leading to uniform machining across different faces. Another reason for the non-uniform machining in the case of the as-fabricated EBM parts is the presence of the columnar grains in the microstructure on the side face along the EBM build direction. This can be observed by comparing the microstructure of the sides faces of the as-fabricated and heat-treated EBM parts, as shown in Fig. 8. Figure 8(a) shows the columnar grains along the EBM build direction, while a uniform microstructure without columnar grains is observed in Fig. 8(b) for the heat-treated part. Columnar grains are formed in the as-fabricated EBM parts due to the high-temperature gradient along the build direction [34]. At the same time for the heat-treated EBM part, the columnar grains disappeared due to the uniform heat provided from all direction for a long time, as shown in Fig. 8(b).

Fig. 9 shows typical 3D scanning surfaces and 2D roughness profiles extracted along the orientations Faces A, Face B, and Face C. It can be observed that, in comparison with face B and face $C$, the 2D roughness profile for the as-fabricated part in Face A orientation is smoother. At the same time, for the machined heat-treated part, there is no significant

\subsection{Micro-hardness}

Figure 10 shows the micro-hardness, performed on the machined surface for the three part orientations for the as-fabricated and heat-treated EBM parts. Figure 10a shows an example of the micro indents taken on the machined surface. It can be observed that for the as-fabricated EBM part there is a significant difference in the micro-hardness between the three-part orientations, as shown in Fig. 10b. This indicates that the EBM component orientations influence the imparted hardness of the machined surface during machining. At the same time, for the EBM part after heat treatment, there is no significant difference in micro-hardness between the three-part orientations, as shown in Fig. 10c. This is because the heat treatment eliminates the effect of EBM part orientation with respect to milling tool feed direction by further fusing/consolidating the EBM layers, diminishing the porosity, and removing the columnar 
grains. The difference in micro-hardness occurs because of the plastic deformation that happened on the machined surface. Since the plastic deformation is dependent on the uniformity of the underlying microstructure. Therefore, due to differences in the microstructure across different faces in the case of the as-fabricated EBM part [20], the variation could be seen in the machined surface hardness (Fig. 10b). In comparison, due to the uniformity of the microstructure in the case of the heat-treated EBM parts, very less micro-hardness variations are produced in the machined surface, as shown in Fig. 10c.

\subsection{Surface morphology}

Figure 11 shows the SEM images of the surface morphology of the EBM part after the milling process for the as-fabricated and heat-treated EBM parts. For the as-fabricated EBM part, It is clear that significant differences exist for the three orientations between the surface morphology (Face $A, B$, and $C$ ). As can be seen from Face $A$, while the tool is being fed through the EBM layer at face $A$, the tool feed marks are minor, as shown in Fig. 11a. This is because, for Face $A$ there are the interfaces between the successive layers, but the interfaces are perpendicular to the direction of the tool feed. A number of layers and layer interfaces covered by the tool were a solid basis for milling. The forces and stress of the tool have thus become more even and the surface texture after milling was smooth. At the same time, the tool feed marks are prominent at face B as the tool moves in parallel with the EBM layers, and there are adhered chips on the machined surface, as shown in Fig. 11b. The layers are parallel to the direction of the tool feed in this case. The contact with the tool along the longitudinal direction was achieved by EBM with several layers. One layer's thickness is in the micron range in the direction of build. A layer had heterogeneous stresses (primarily stresses on compressive and shear) as a result of the mechanical forces of the tool until the material eventually broke and was removed as chips. Since two consecutive layers have an interface and the ultimate interface strength may be smaller than the one in a single layer, the mechanical stresses induced by the tool were not consistently distributed. For face $C$, the feed tool marks are large when the tool is fed into the EBM layer plane. In addition, micro-chips and micro-pits welded on the surface are generated, as shown in Fig. 11c.

In Face C, the EBM layers are in-plane to the tool feed direction (TFD). The thickness of the layer for molten powder was set to $50 \mu \mathrm{m}$ through the electron beam and the depth of cut was applied in the milling process to $0.4 \mathrm{~mm}(400 \mu \mathrm{m})$. A single milling tool pass therefore eliminates several layers. The powder should be melted uniformly since the melting depth of Ti6Al4V powder in one layer is around 50 $\mu \mathrm{m}$. Therefore, the surface integrity of the solidified layers on the machined part's side only depends on a single layer on Face $\mathrm{C}$. The combination of multiple layers on this face does not have any effect. The effects of EBM's workpiece orientation when the direction of the feed was in Face $C$ shown in Fig. 11c. In this case thick marks of feed are visible in comparison to Face $A$ and Face $B$, giving a large surface roughness (after milling). Furthermore, compared with Face $A$ and Face $B$, the micro-pit is more significant. The Face $B$ and Face $C$ orientations are therefore not sufficient for milling in order to enhance surface finish.

For the heat-treated EBM parts, there are no significant differences between the three orientations (Face A, Face B, and Face C) and the tool feed marks are minor, as shown in Fig. 11 (d, e, f). This is because the 
layers become closer to each other, i.e., more consolidated, and consequently, the machining becomes more uniform. Moreover, there is a clear indication that the porosity has a more dominant effect on the surface integrity of the machined samples [38]. The decrease in porosity of the heat-treated EBM part (see Fig. 7b) leads to a machined surface with minor feed marks and without micro-chips welded on the surface. The presence of more deposited chips on the machined surfaces in the case of the as-fabricated parts is attributed to the presence of porosity (see Fig. 7a) as reported by [38]. The surface integrity defects are summarized in Table 4 for the as-fabricated and heat-treated EBM parts.

For an as-fabricated EBM component, careful consideration should be given to the selection of the required EBM part orientation regarding the milling tool feed direction to improve surface quality. At the same time, in the case of the heat-treated EBM part, the effect of part orientation with respect to the milling tool feed direction was almost removed.

\section{Table 4}

Key occurrence of defects for the as-fabricated and heat-treated EBM parts. Incidence scale: $\mathbf{0}=$ weak, $=$ moderate,$\bigcirc \bigcirc=$ large.

\begin{tabular}{|c|c|c|c|c|c|c|}
\hline \multirow[t]{2}{*}{ Defects } & \multicolumn{3}{|c|}{ As-fabricated EBM part } & \multicolumn{3}{|c|}{ Heat-treated EBM part } \\
\hline & Face A & Face B & Face C & Face A & Face B & Face C \\
\hline Adhered chips & - & $\bullet \bullet$ & 0 & 0 & 0 & 0 \\
\hline Micro-chips welded on the surface & 00 & 0 & $\bullet \circ$ & 0 & 0 & 0 \\
\hline Thick tool feed marks & 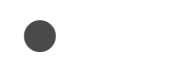 & 00 & 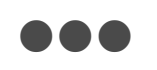 & 0 & 0 & 0 \\
\hline
\end{tabular}

\section{Conclusion}

This paper has presented the results of milling tests by considering the EBM part/layers' orientation effect. Heat treatment was employed to the as-fabricated EBM parts to suppress the effect of the EBM part orientations during machining. Heat treatment was applied in such a way that it retained the superior microstructure of the as-fabricated parts. The milling performance was compared for the as-fabricated and heat-treated EBM parts in terms of the surface roughness, micro-hardness, microstructure and surface morphology. The results revealed that the heat-treated EBM parts are more appropriate for producing uniform surface quality on all the faces. On the contrary, the as-fabricated EBM parts produced varying surface quality on different faces during milling for the same machining parameters. Some of the major findings are summarized below.

- Three different recipes were used to heat treat the as-fabricated EBM parts; $950^{\circ} \mathrm{C} / 2 \mathrm{~h}, 850^{\circ} \mathrm{C} / 2 \mathrm{~h}$, and $600^{\circ} \mathrm{C} / 3 \mathrm{~h}$, based upon their suitability to produce the lamellar $\mathrm{a}+\beta$ microstructure. However, only $600^{\circ} \mathrm{C} / 3 \mathrm{~h}$ heat treatment succeeded to preserve both the microstructure and hardness as that of the as-fabricated EBM Ti6Al4V parts. 
- Regarding the surface roughness, in the case of the as-fabricated EBM part, a significant difference of $27 \%$ was noted between the highest roughness value of Face $C$ and the lowest value of Face $A$. Whereas, in the case of the heat-treated EBM part, a uniform surface roughness was produced for all the Faces/part orientations with a difference of $8 \%$.

- The porosity in the heat-treated EBM parts was significantly less than the as-fabricated EBM parts. Furthermore, there is a difference in the microstructure across different faces in the case of the asfabricated EBM part. At the same time, the uniformity of the microstructure in the case of the heattreated EBM parts was obtained.

- Contrary to the as-fabricated EBM parts, the variation (18\%) of the micro-hardness among all the Faces was reduced to insignificant $(2 \%)$ when the milling was performed for the heat-treated part.

- The as-fabricated milled EBM part showed varying surface morphology for different Faces with indications of welded micro to macro-sized chips and fluctuating minor to thick tool feed marks. In contrast, only minor tool feed marks and some micro-redeposited chips were observed after milling of the heat-treated EBM part for any Faces/layers' orientations.

\section{Declarations}

Author contribution Conceptualization: Abdulmajeed Dabwan, Saqib Anwar, Ali M. Al-Samhan; Methodology: Abdulmajeed Dabwan, Saqib Anwar; Investigations: Abdulmajeed Dabwan, Mustafa M. Nasr; Writing original draft: Abdulmajeed Dabwan; Writing, review, and editing: Abdulmajeed Dabwan, Saqib Anwar, Ali M. Al-Samhan.

Funding This research was funded by the Deanship of Scientific Research, King Saud University: research group no. RG-1438-088.

Acknowledgement The authors extend their appreciation to the Deanship of Scientific Research at King Saud University for funding this work through research group no. RG-1438-088.

Availability of data and materials All data generated or analyzed during this study are included in the present article.

Ethics approval The article follows the guidelines of the Committee on Publication Ethics (COPE) and involves no studies on human or animal subjects.

Consent to participate Not applicable.

Consent to Publish The authors confirm that the publication of the paper has been approved by all coauthors.

Competing interests The authors declare no competing interests.

\section{References}


1. Boyer RR (1996) An overview on the use of titanium in the aerospace industry. Mater Sci Eng $A$ 213:103-114. https://doi.org/10.1016/0921-5093(96)10233-1

2. Lütjering G, Williams J Titanium. 2 ed2007. New York Springer

3. Calamaz M, Coupard D, Girot F (2008) A new material model for 2D numerical simulation of serrated chip formation when machining titanium alloy Ti-6Al-4V. Int J Mach Tools Manuf 48:275-288. https://doi.org/10.1016/j.ijmachtools.2007.10.014

4. Galarraga H, Lados DA, Dehoff RR et al (2016) Effects of the microstructure and porosity on properties of Ti-6Al-4V ELI alloy fabricated by electron beam melting (EBM). Addit Manuf 10:47-57. https://doi.org/10.1016/j.addma.2016.02.003

5. Bordin A, Bruschi S, Ghiotti A et al (2014) Comparison between wrought and EBM Ti6Al4V machinability characteristics. Key Eng Mater 611-612:1186-1193. https://doi.org/10.4028/www.scientific.net/KEM.611-612.1186

6. Gibson I (2006) Advanced manufacturing technology for medical applications: reverse engineering, software conversion and rapid prototyping

7. Galarraga H, Warren RJ, Lados DA et al (2017) Effects of heat treatments on microstructure and properties of Ti-6Al-4V ELI alloy fabricated by electron beam melting (EBM). Mater Sci Eng A 685:417-428. https://doi.org/10.1016/j.msea.2017.01.019

8. Dolimont A, Michotte S, Rivière-Lorphèvre $E$ et al (2017) Influence on surface characteristics of electron beam melting process (EBM) by varying the process parameters. In: AIP Conference Proceedings. American Institute of Physics Inc

9. Anwar S, Ahmed N, Abdo BM et al (2018) Electron beam melting of gamma titanium aluminide and investigating the effect of EBM layer orientation on milling performance. Int J Adv Manuf Technol 96:3093-3107. https://doi.org/10.1007/s00170-018-1802-7

10. Anwar S, Ahmed N, Pervaiz S et al (2020) On the turning of electron beam melted gamma-TiAl with coated and uncoated tools: A machinability analysis. J Mater Process Technol 282:116664. https://doi.org/10.1016/j.jmatprotec.2020.116664

11. Al-Rubaie KS, Mario Fernandes Paiva JJ, Veldhuis S et al (2020) Machinability of SLM-produced Ti6Al4V titanium alloy parts Control the micro-adhesion during machining different stainless steels View project Artificial Intelligent based Tool Condition Monitoring (TCM) in Machining View project Machinability of SLM-prod. Artic J Manuf Process. https://doi.org/10.1016/j.jmapro.2020.07.035

12. Jawahir IS, Brinksmeier E, M'Saoubi R et al (2011) Surface integrity in material removal processes: Recent advances. CIRP Ann - Manuf Technol 60:603-626. https://doi.org/10.1016/j.cirp.2011.05.002

13. Sun J, Guo YB (2009) A comprehensive experimental study on surface integrity by end milling Ti-6Al4V. J Mater Process Technol 209:4036-4042. https://doi.org/10.1016/j.jmatprotec.2008.09.022

14. Che-Haron $\mathrm{CH}$, Jawaid $\mathrm{A}$ (2005) The effect of machining on surface integrity of titanium alloy $\mathrm{Ti}-6 \%$ Al-4\% v. J Mater Process Technol 166:188-192. https://doi.org/10.1016/j.jmatprotec.2004.08.012 
15. Narutaki N, Murakoshi A, Motonishi S, Takeyama H (1983) Study on Machining of Titanium Alloys. CIRP Ann - Manuf Technol 32:65-69. https://doi.org/10.1016/S0007-8506(07)63362-9

16. KE Y, lin DONGH, yue LIUG, ZHANG M (2009) Use of nitrogen gas in high-speed milling of Ti-6Al-4V. Trans Nonferrous Met Soc China (English Ed 19:530-534. https://doi.org/10.1016/S10036326(08)60307-6

17. Shokrani A, Dhokia V, Newman ST (2016) Investigation of the effects of cryogenic machining on surface integrity in CNC end milling of Ti-6Al-4V titanium alloy. J Manuf Process 21:172-179. https://doi.org/10.1016/j.jmapro.2015.12.002

18. Milton S, Morandeau A, Chalon F, Leroy R (2016) Influence of Finish Machining on the Surface Integrity of Ti6Al4V Produced by Selective Laser Melting. Procedia CIRP 45:127-130. https://doi.org/10.1016/j.procir.2016.02.340

19. Simonelli M, Tse YY, Tuck C (2014) Effect of the build orientation on the mechanical properties and fracture modes of SLM Ti-6Al-4V. Mater Sci Eng A 616:1-11.

https://doi.org/10.1016/j.msea.2014.07.086

20. Dabwan A, Anwar S, Al-Samhan M, Nasr AM M (2020) On the Effect of Electron Beam Melted Ti6Al4V Part Orientations during Milling. Metals (Basel) 10:1172. https://doi.org/10.3390/met10091172

21. De Formanoir C, Michotte S, Rigo 0 et al (2015) Author's Accepted Manuscript Electron beam melted Ti-6Al-4V: microstructure, texture and mechanical behavior of the as-built and heat-treated material. Elsevier. https://doi.org/10.1016/j.msea.2015.11.052

22. Raghavan S, Ling M, Nai S et al (2018) Heat treatment of electron beam melted (EBM) Ti-6Al-4V: microstructure to mechanical property correlations. emeraldcom 24:774-783. https://doi.org/10.1108/RPJ-05-2016-0070

23. ZHANG Q, LIANG Z long CAOM et al (2017) Microstructure and mechanical properties of Ti6Al4V alloy prepared by selective laser melting combined with precision forging. Trans Nonferrous Met Soc China (English Ed 27:1036-1042. https://doi.org/10.1016/S1003-6326(17)60121-3

24. Mohammadhosseini A, Fraser D, Masood SH, Jahedi M (2013) Microstructure and mechanical properties of Ti-6Al-4V manufactured by electron beam melting process. Mater Res Innov 17:. https://doi.org/10.1179/1432891713Z.000000000302

25. Roy S, Suwas S, Tamirisakandala S et al (2011) Development of solidification microstructure in boron-modified alloy Ti-6Al-4V-0.1B. Acta Mater 59:5494-5510. https://doi.org/10.1016/j.actamat.2011.05.023

26. Ameen W, Al-Ahmari A, Mohammed MK (2019) Self-supporting overhang structures produced by additive manufacturing through electron beam melting. Int J Adv Manuf Technol 104:2215-2232. https://doi.org/10.1007/s00170-019-04007-3

27. Umer U, Ameen W, Abidi MH et al (2019) Modeling the Effect of Different Support Structures in Electron Beam Melting of Titanium Alloy Using Finite Element Models. Metals (Basel) 9:806. https://doi.org/10.3390/met9070806 
28. The Importance of Surface Finish in Components for The Aerospace and ... https://www.slideshare.net/nuclead/the-importance-of-surface-finish-in-components-for-theaerospace-and-medical-industries. Accessed 21 Sep 2020

29. Galanis NI, Manolakos DE (2009) Surface roughness of manufactured femoral heads with high speed turning. Int J Mach Mach Mater 5:371-382. https://doi.org/10.1504/IJMMM.2009.026898

30. Liu H, Wu C, Chen R (2011) Effects of cutting parameters on the surface roughness of Ti6Al4V titanium alloys in side milling. In: Solid State Phenomena. Trans Tech Publications Ltd, pp 289-293

31. Oosthuizen GA, Nunco K, Conradie PJT, Dimitrov DM (2016) The effect of cutting parameters on surface integrity in milling TI6AL4V. South African. J Ind Eng 27:115-123.

https://doi.org/10.7166/27-4-1199

32. Abbasi SA, Feng P, Ma Y et al (2016) Influence of microstructure and hardness on machinability of heat-treated titanium alloy Ti-6Al-4V in end milling with polycrystalline diamond tools. Int $\mathrm{J} \mathrm{Adv}$ Manuf Technol 86:1393-1405. https://doi.org/10.1007/s00170-015-8245-1

33. Yu G, Li Z, Hua Y et al (2020) The effects of post heat treatment on the microstructural and mechanical properties of an additive-manufactured porous titanium alloy. Materials (Basel) 13:. https://doi.org/10.3390/ma13030593

34. Wang J, Lin X, Wang M et al (2020) Effects of subtransus heat treatments on microstructure features and mechanical properties of wire and arc additive manufactured Ti-6Al-4V alloy. Mater Sci Eng A 776:139020. https://doi.org/10.1016/j.msea.2020.139020

35. Zhang LC, Liu Y, Li S, Hao Y (2018) Additive Manufacturing of Titanium Alloys by Electron Beam Melting: A Review. Adv Eng Mater 20:1-16. https://doi.org/10.1002/adem.201700842

36. Syed AK, Awd M, Walther F, Zhang X (2019) Microstructure and mechanical properties of as-built and heat-treated electron beam melted $\mathrm{Ti}-6 \mathrm{Al}-4 \mathrm{~V}$. 0836:

https://doi.org/10.1080/02670836.2019.1580434

37. Murr LE, Esquivel EV, Quinones SA et al (2009) Microstructures and mechanical properties of electron beam-rapid manufactured Ti-6Al-4V biomedical prototypes compared to wrought Ti-6Al-4V. Mater Charact 60:96-105. https://doi.org/10.1016/j.matchar.2008.07.006

38. Sobiyi KK, Blaine DC (2011) MACHINING OF POWDER METAL TITANIUM

\section{Figures}




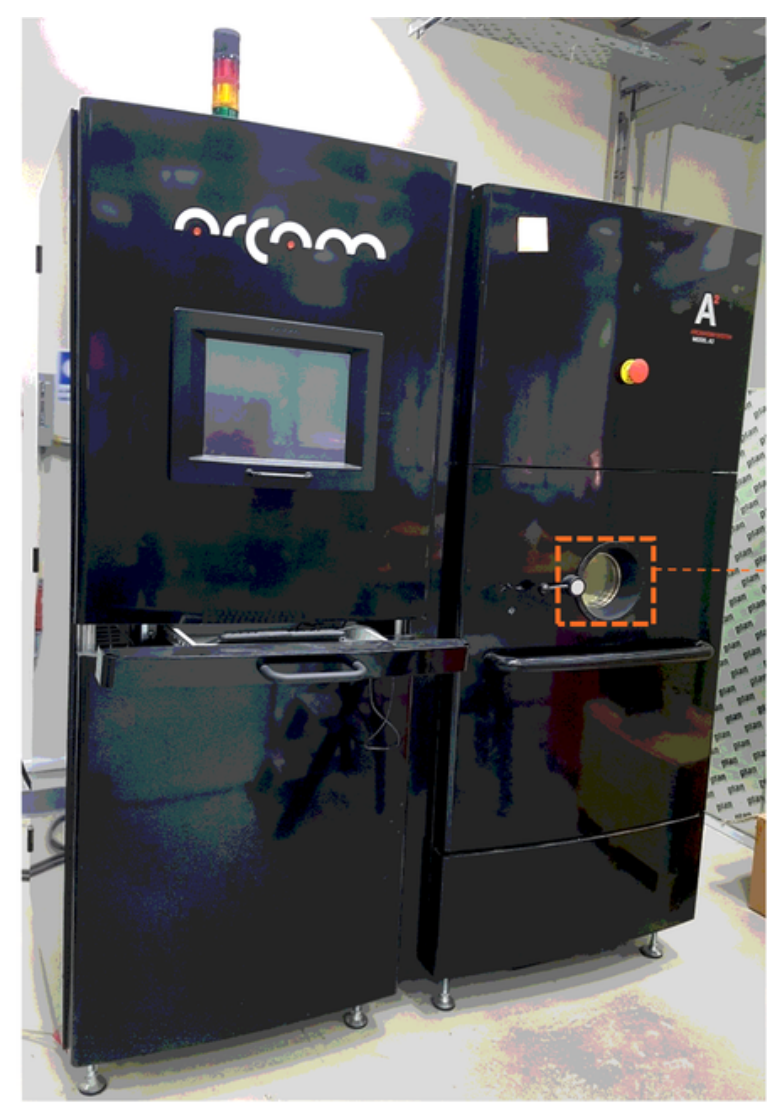

(a)

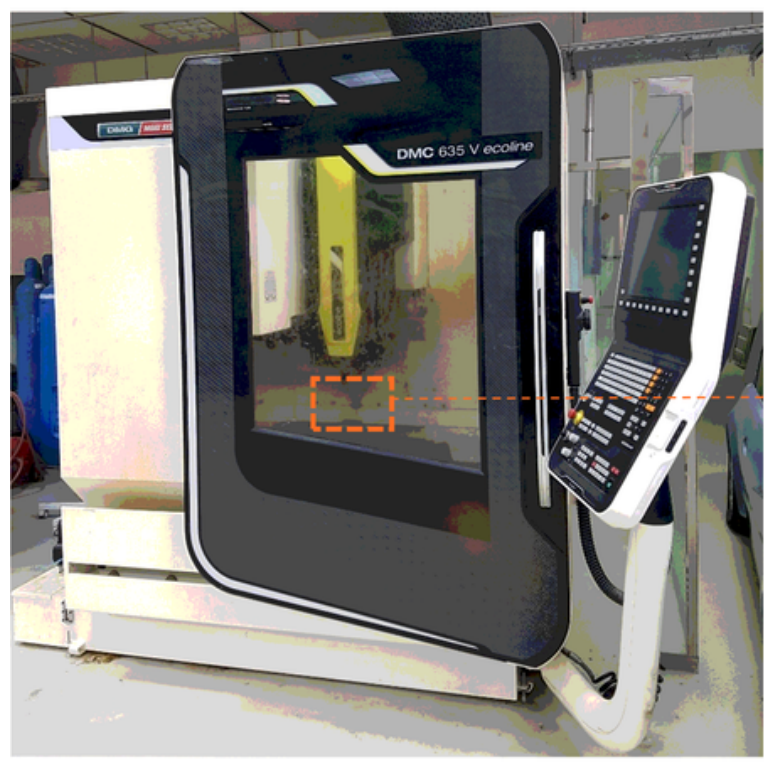

(c)

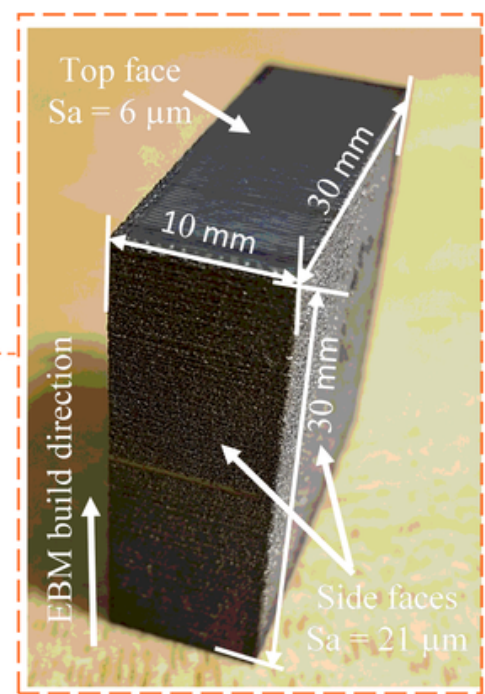

(b)

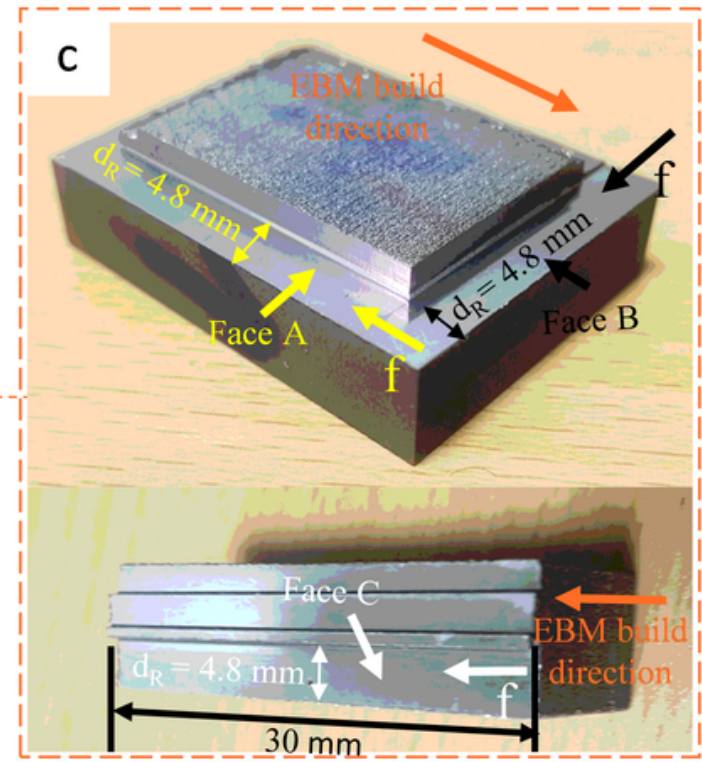

(d)

\section{Figure 1}

(a) ARCAM EBM machine, (b) 3D part fabricated through EBM, (c) 3-axis DMG CNC milling machine, and (d) a milled part with labeled various orientations. $(\mathrm{dR}=$ radial depth of cut, $f=$ feed rate $)$ 

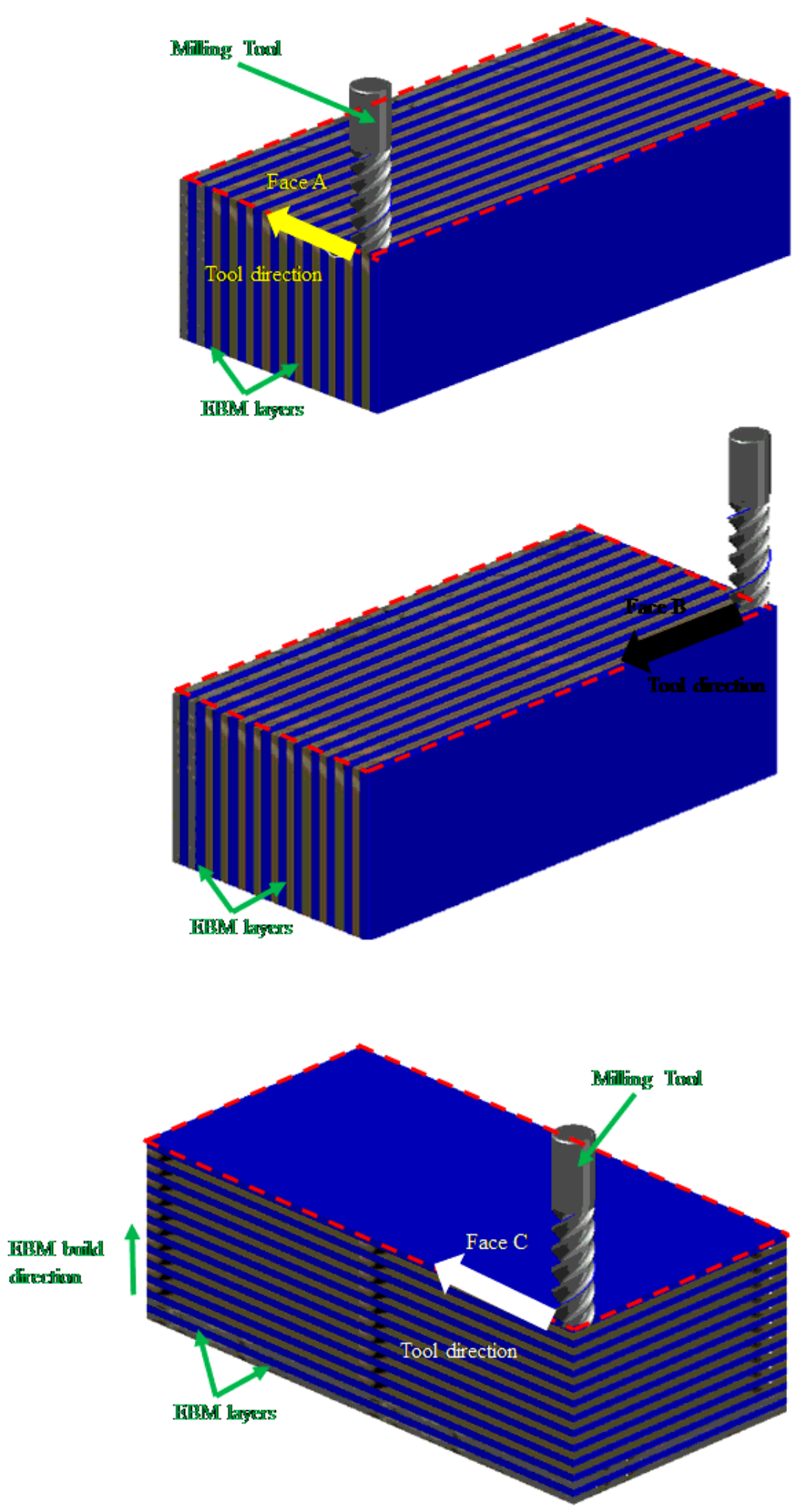

Figure 2

Possible EBM part/layers' orientation for milling. 

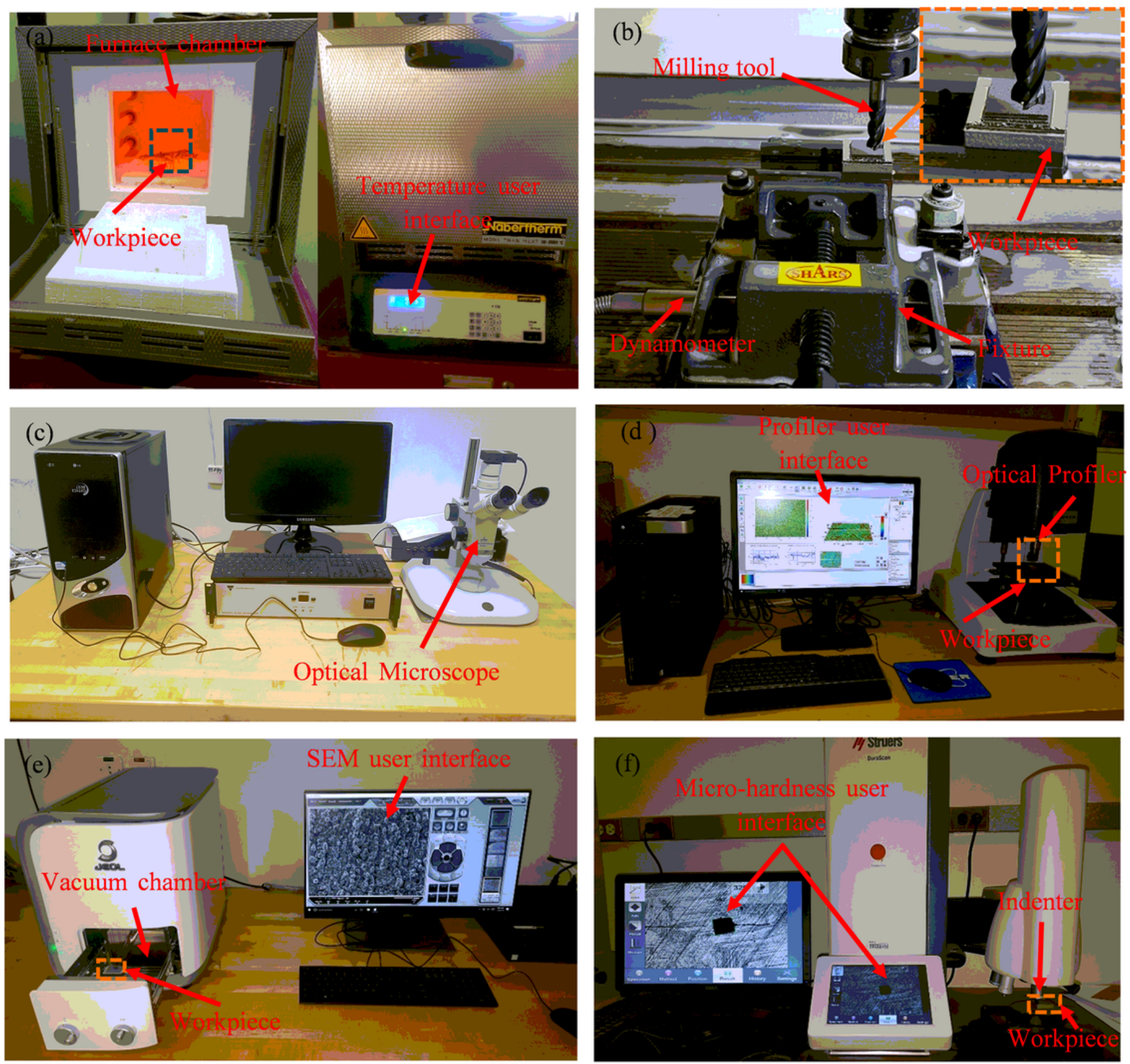

\section{Figure 3}

a. Heat treatment furnace setup. b. Machining process setup. c. Dynamometer setup. d. 3D optical profilometer setup. e. SEM setup to study the surface morphology. f. Micro-hardness measurement setup. 

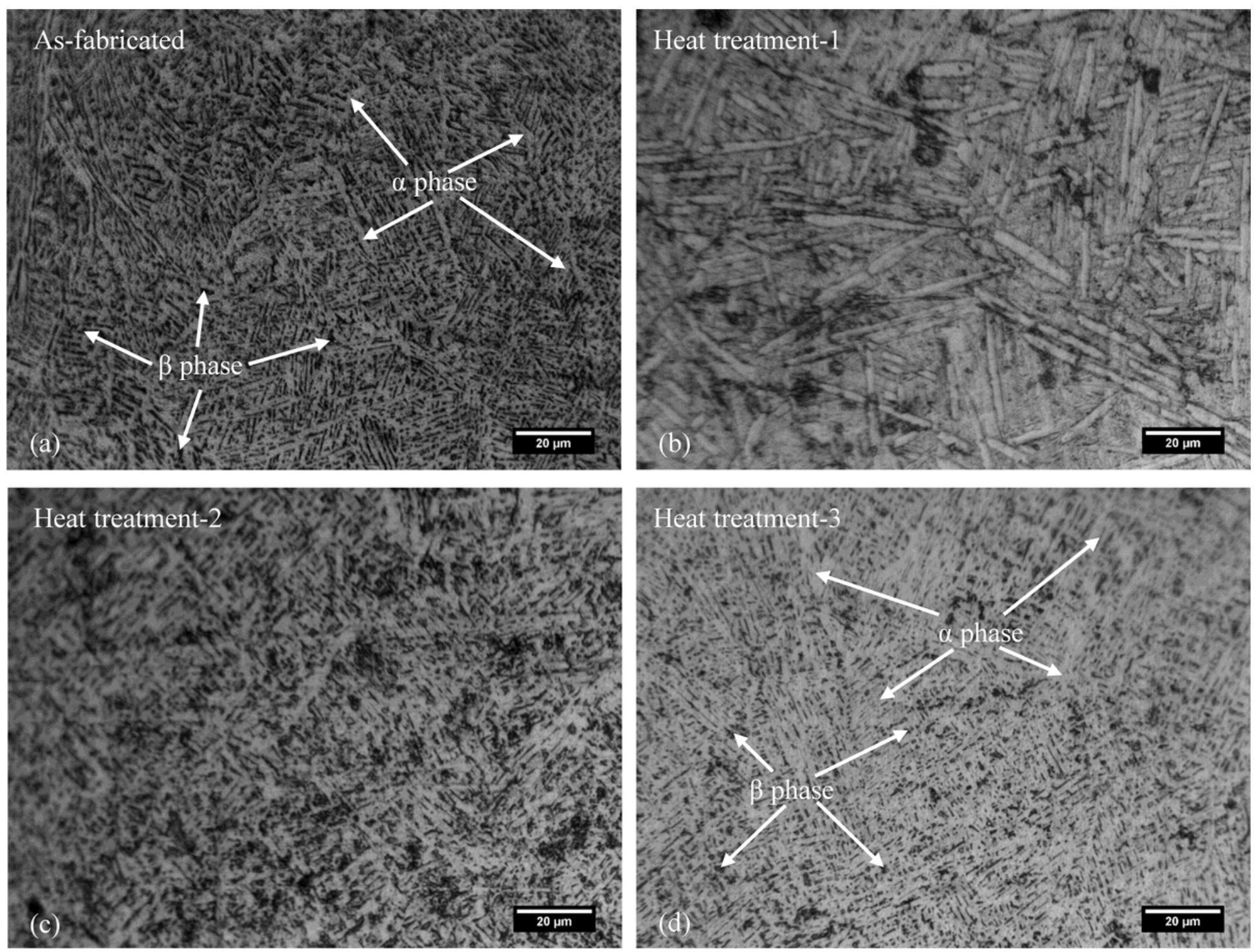

\section{Figure 4}

Optical microscope images of the microstructures for, a. As-fabricated EBM part, b. Heat-treated EBM part at $950^{\circ} \mathrm{C}$ for $2 \mathrm{~h}$, air-cooled, c. Heat-treated EBM part at $850^{\circ} \mathrm{C}$ for $2 \mathrm{~h}$, air-cooled, and d. Heat-treated EBM part at $600^{\circ} \mathrm{C}$ for $3 \mathrm{~h}$, air-cooled. 


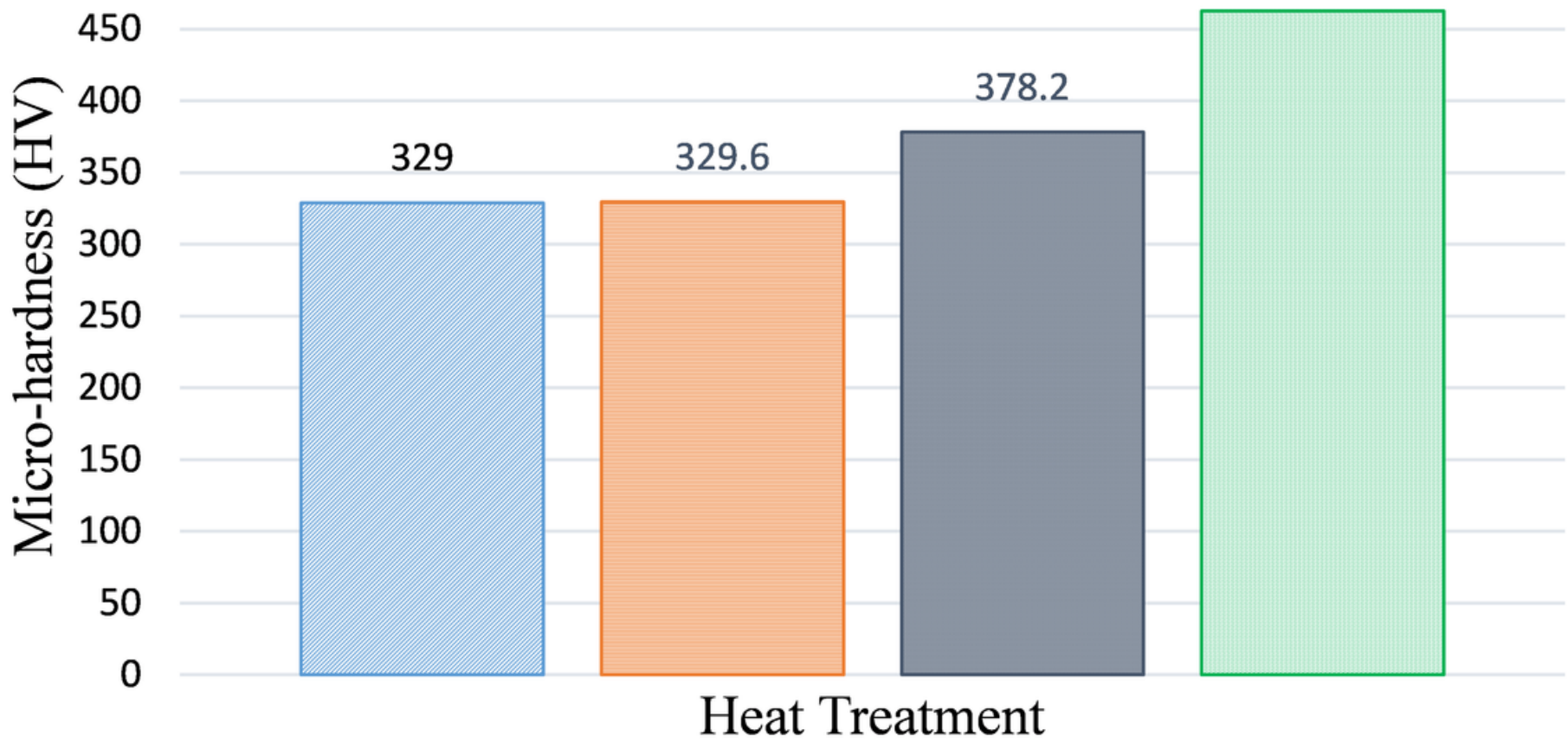

$\square$ As-fabricated $\quad \square 600{ }^{\circ} \mathrm{C} / 3 \mathrm{~h} \quad \square 850{ }^{\circ} \mathrm{C} / 2 \mathrm{~h} \quad \square 950{ }^{\circ} \mathrm{C} / 2 \mathrm{~h}$

\section{Figure 5}

Micro-hardness of the as-fabricated part and heat-treated EBM parts.

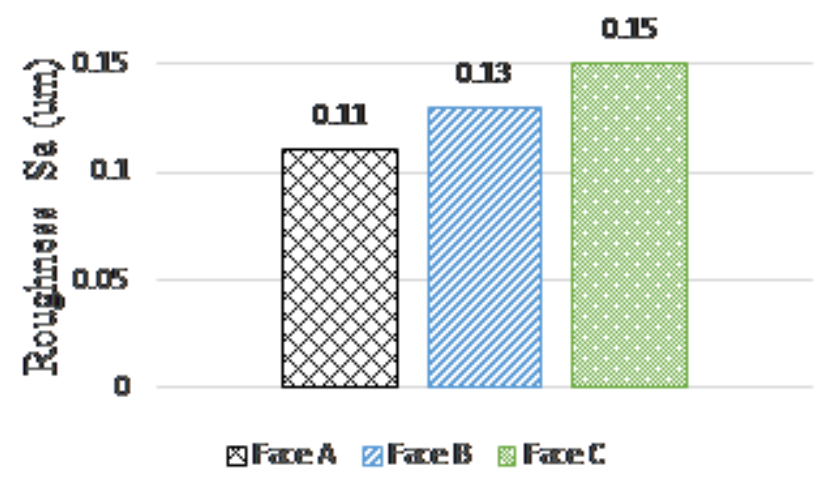

(a)

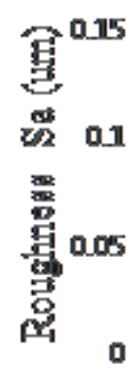

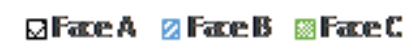

(b)

Figure 6

Surface roughness at $V=80 \mathrm{~m} / \mathrm{min}, f=30 \mathrm{~mm} / \mathrm{min}, \mathrm{dA}=0.4 \mathrm{~mm}$, and $\mathrm{dR}=4.8 \mathrm{~mm}$ for the three part orientations, a. as-fabricated part and $\mathrm{b}$. heat-treated part. 


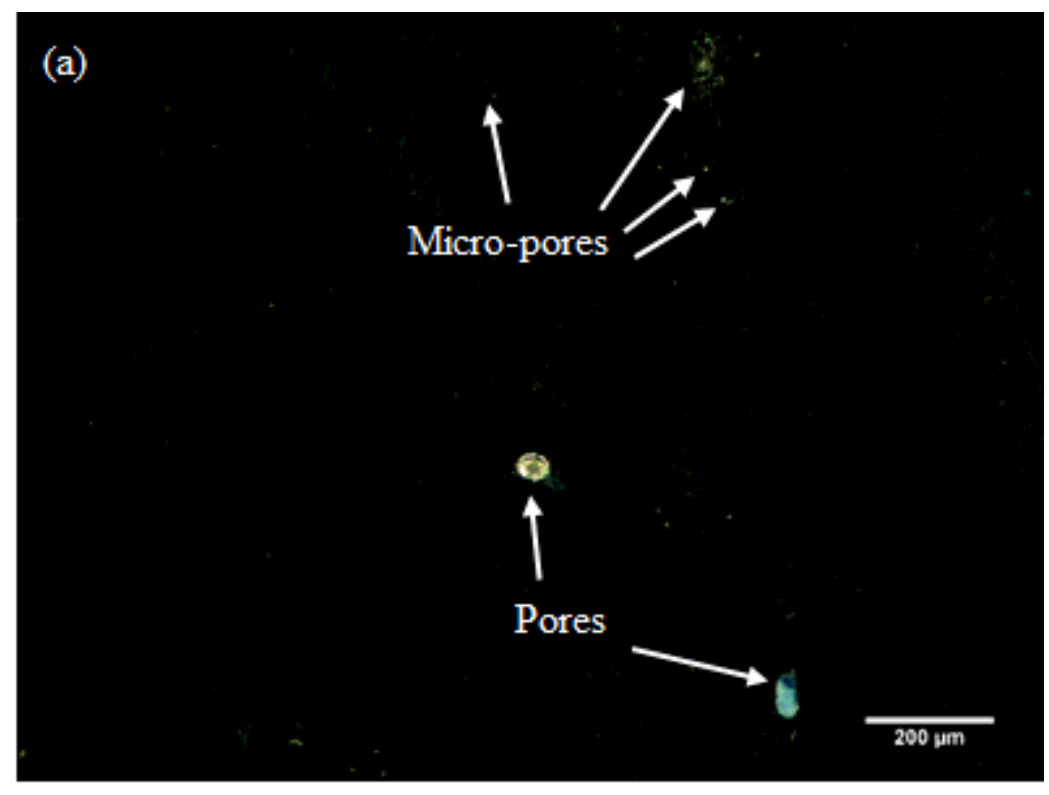

(b)

\section{Figure 7}

Optical microscope images of the porosity for, a. as-fabricated EBM part, b. heat-treated EBM part at $600^{\circ} \mathrm{C}$ for $3 \mathrm{~h}$, air-cooled. 

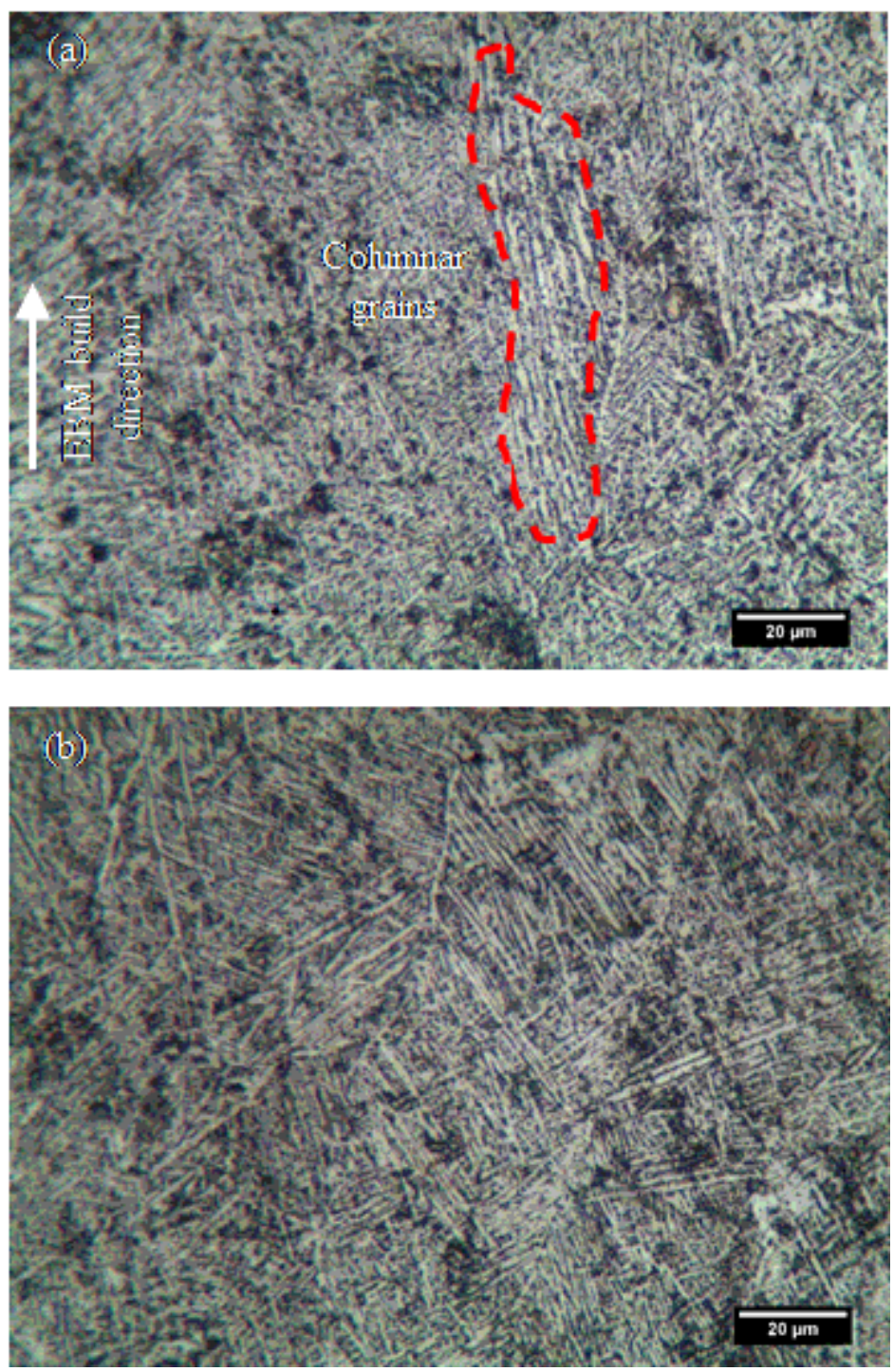

\section{Figure 8}

Optical microscope images of the microstructures for, a. side face of the as-fabricated EBM part, $b$. and a side face of the heat-treated EBM part at $600^{\circ} \mathrm{C}$. 

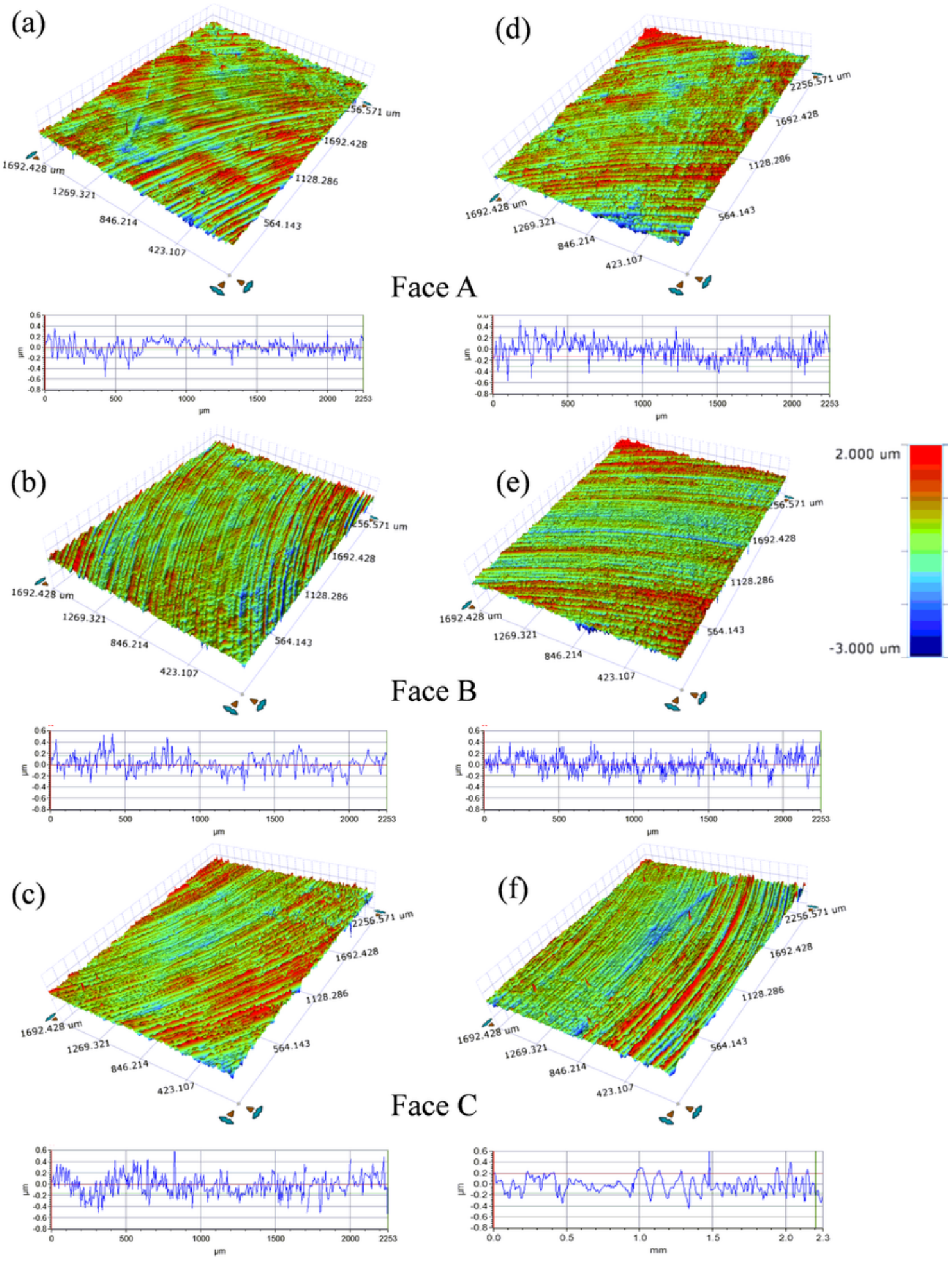

\section{Figure 9}

$3 D$ scanned surfaces and the extracted $2 D$ roughness profiles at $V=80 \mathrm{~m} / \mathrm{min}, f=30 \mathrm{~mm} / \mathrm{min}, \mathrm{dA}=0.4$ $\mathrm{mm}$, and $\mathrm{dR}=4.8 \mathrm{~mm}$ for the three part orientations, a, b, c. as-fabricated EBM part, and d, e, f. heattreated part. 

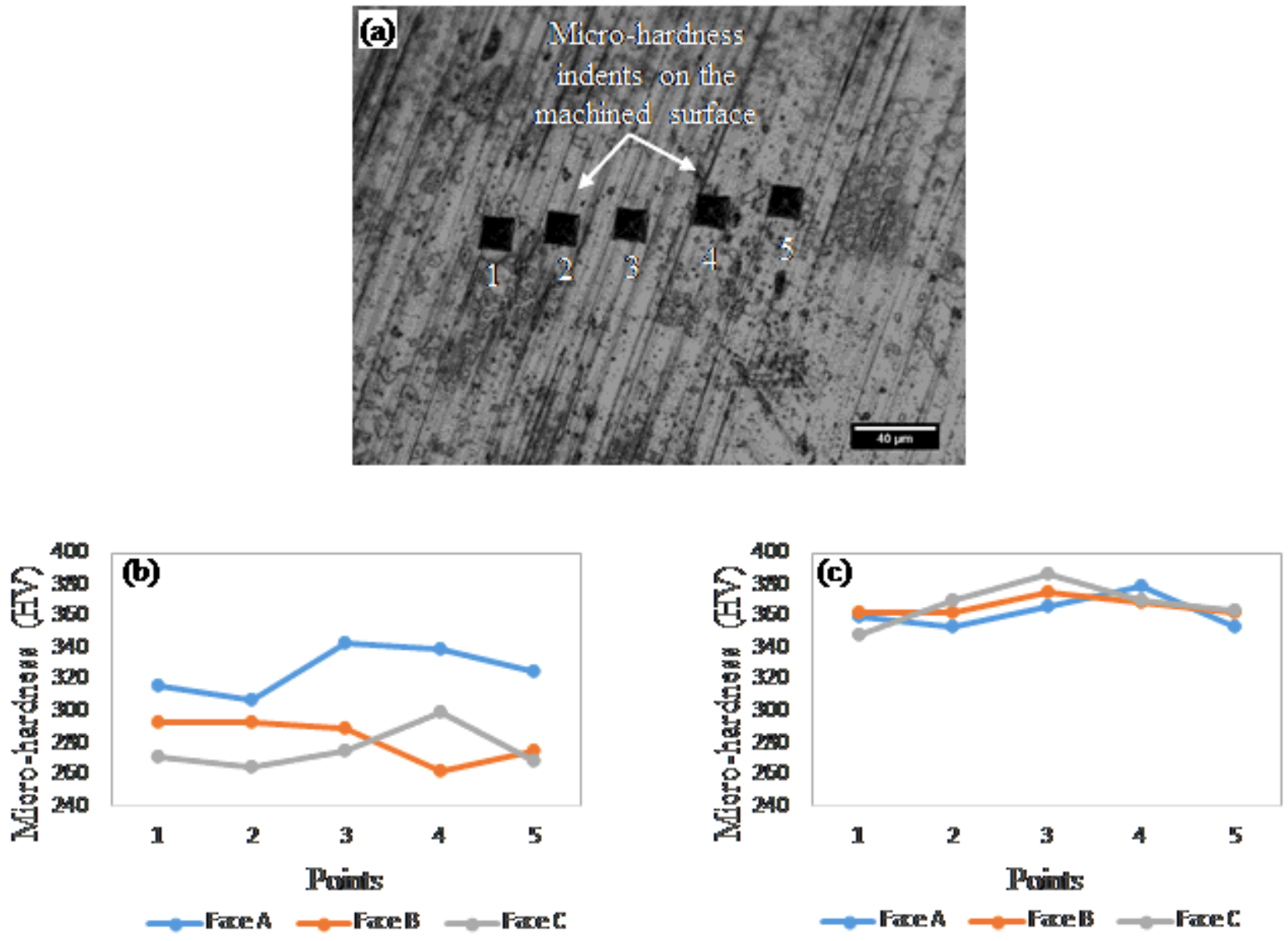

Figure 10

a. Micro-hardness tests performed on the machined sample at $V=50 \mathrm{~m} / \mathrm{min}, \mathrm{f}=30 \mathrm{~mm} / \mathrm{min}, \mathrm{dA}=0.6$ $\mathrm{mm}$, and $\mathrm{dR}=4.8 \mathrm{~mm}$ at b. as-fabricated part and c. heat-treated part. 

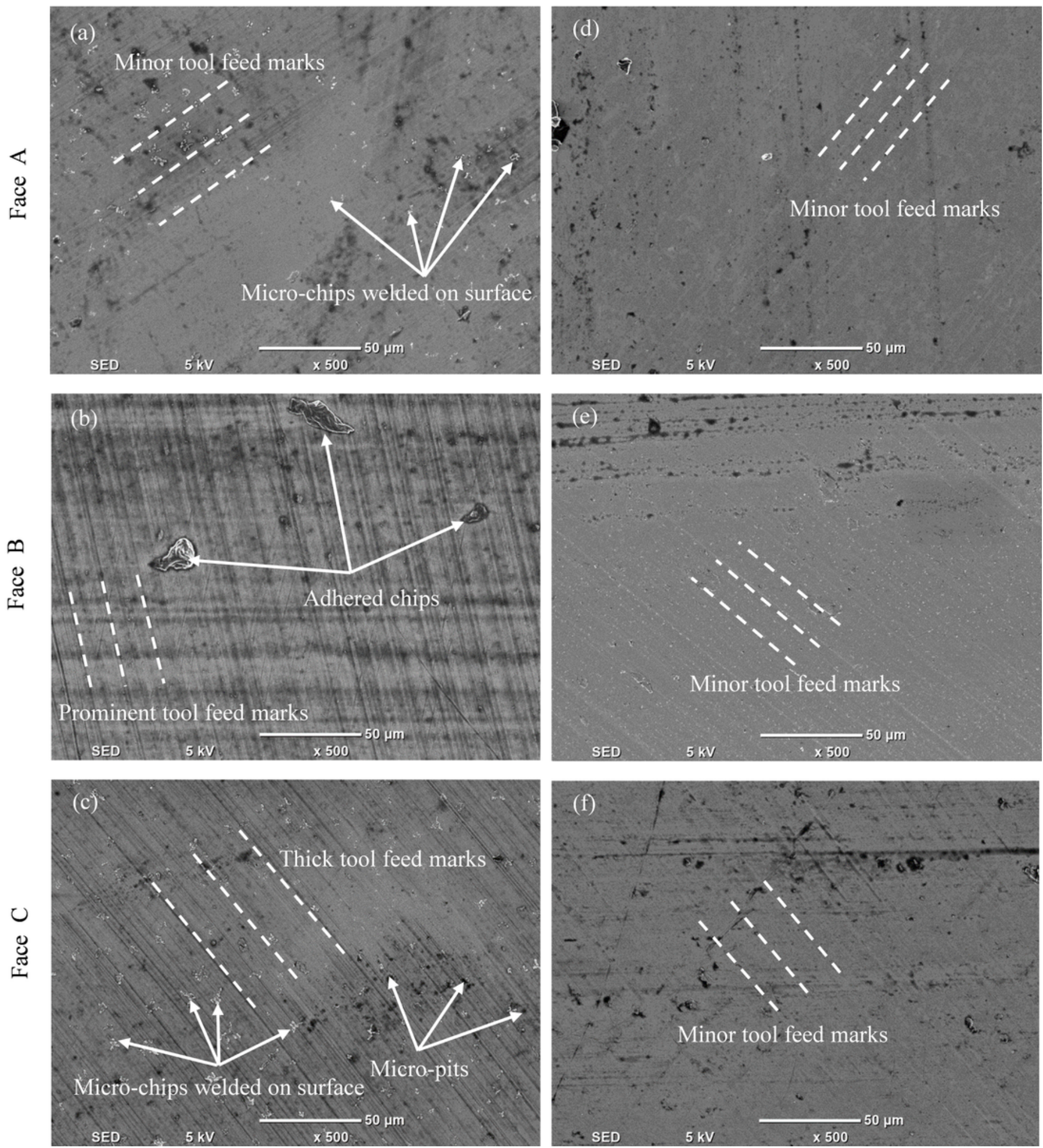

\section{Figure 11}

SEM image for milled surface at $V=50 \mathrm{~m} / \mathrm{min}, \mathrm{f}=30 \mathrm{~mm} / \mathrm{min}, \mathrm{dA}=0.6 \mathrm{~mm}$, and $\mathrm{dR}=4.8 \mathrm{~mm}$ for the three part orientations at a, b, c. as-fabricated part and d, e, f. heat-treated part. 